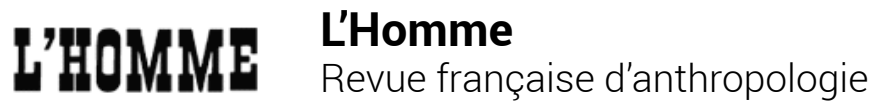

164 | octobre-décembre 2002

Histoire, littérature et ethnologie

\section{Mireille Lecarme-Frassy, Marchandes dakaroises \\ entre maison et marché. Approche anthropologique}

Paris, L'Harmattan, 2000, 270 p., annexes, bibl. (« Études africaines »).

Marie-Claude Dupré

\section{OpenEdition}

\section{Journals}

Édition électronique

URL : https://journals.openedition.org/lhomme/14102

DOI : 10.4000//homme.14102

ISSN : 1953-8103

Éditeur

Éditions de l'EHESS

Édition imprimée

Date de publication : 1 décembre 2002

Pagination : 157-159

ISBN : 2-7132-1775-X

ISSN : 0439-4216

Référence électronique

Marie-Claude Dupré, « Mireille Lecarme-Frassy, Marchandes dakaroises entre maison et marché

Approche anthropologique », L'Homme [En ligne], 164 I octobre-décembre 2002, mis en ligne le 25 mars 2008, consulté le 24 avril 2022. URL : http://journals.openedition.org//homme/14102 ; DOI : https:// doi.org/10.4000/lhomme.14102

Ce document a été généré automatiquement le 24 avril 2022

(C) École des hautes études en sciences sociales 


\title{
Mireille Lecarme-Frassy, Marchandes dakaroises entre maison et marché. Approche anthropologique
}

\author{
Paris, L'Harmattan, 2000, 270 p., annexes, bibl. (« Études africaines »).
}

\author{
Marie-Claude Dupré
}

1 L'APPROCHE anthropologique choisie par Mireille Lecarme-Frassy s'inscrit au départ, « au carrefour des désarrois intellectuels» (p.7). Cette belle expression forgée par Marc Augé en 1979 introduit bien à la situation de l'anthropologie des années 1980, celles au cours desquelles se sont échelonnées les enquêtes de l'auteur sur les marchandes de poisson dans le marché précaire du quartier de Dalifort à Dakar. C'est la période où les réalités africaines échappent à une recherche encore soumise au présent ethnographique, visant la connaissance de sociétés postulées cohérentes. Les observateurs se déplacent vers les villes et, face à une réalité nouvelle, se voient obligés d'inventer des approches nouvelles marquées du sceau du multiple: ce sont les premiers pas de la pluridisciplinarité, avec des emprunts aux franges de la sociologie et de la linguistique, à l'ethnométhodologie, à la biographie ainsi qu'aux études de genre alors en plein essor.

2 Une enquête étalée sur quatre ans, un retour dix ans plus tard donnent à ce travail une profondeur temporelle propre à répondre à l'interrogation lancinante des mois passés dans le tumulte bigarré du marché où s'affrontent vendeuses et clientes liées par un antagonisme aussi passager que nécessaire, les premières souhaitant réaliser leur bénéfice, les secondes réussissant parfois à obtenir du poisson en dessous de son prix d'achat. Le tout restant soumis à la pauvreté de multiples manières: précarité du quartier et de son marché, détresse économique des marchandes et des clientes; pression inouïe exercée par la moitié masculine de la société, trop souvent dépourvue de ressources monétaires, sur les femmes dont la force morale et physique devient ainsi le dernier rempart contre l'indigence; pression que les mères reportent sur leurs filles en leur demandant des services nécessaires à la survie: transporter, vendre, être servantes (fillette de huit ans renvoyée parce qu'elle ne sait pas repasser des vêtements 
d'adulte avec le fer à charbon de nos arrière-grands-mères). D'entrée, Mireille LecarmeFrassy se demande comment persiste cet habitus, comment il s'est formé, et s'il évolue vers une certaine autonomie de la moitié féminine.

3 Cette question sous-jacente enrichit l'exercice, vivement mené, qui nous restitue la vie agitée, impérieuse, ludique qui se donne à voir, avec une théâtralisation certaine, dans les échanges marchands où le gain monétaire, pourtant bien peu régulier, est une nécessité absolue. Grâce à la pluridisciplinarité de l'approche, l'économie informelle est présentée sous tous ses aspects: agressivité des clientes, «honte» des vendeuses, plaisanteries parfois féroces pimentant un canevas préétabli d'échanges verbaux, éclats de voix et paroles codées qui dévoilent brusquement les hiérarchies sociales entre griottes et femmes riches, entre Peuls, Sérères, gens du fleuve et peuples de Casamance, entre vendeuses débutantes et marchandes aguerries. Et, pour celle qui sait les voir, les traces imperceptibles de "maraboutage ", cette malfaisance constitutive des rapports sociaux chargés de jalousie. Sur cette arène de violence, lourde d'agressivité interindividuelle et de contrainte économique, plane cependant l'ombre impérative de la paix du marché et de la bonne entente obligatoire.

C'est cette contrainte économique, relayée par les rapports hommes-femmes et mèresfilles, qui semble maintenir la dépendance féminine. L'économie informelle ne se réduit pas à la vente de poisson qui rapporte, au minimum, les protéines du repas vespéral. Les apprentissages domestiques s'enrichissent de pluri-commerces (boulettes de poisson séché, tabac à priser, beignets, poisson frit) évoluant vers des activités alternatives (gargotes, bistrots clandestins, lessive et repassage, voire broderie), accompagnées de ressources parallèles (élevage de canards et de moutons, jardinage). En une dizaine de pages, l'auteur donne un aperçu des différentes tontines qui regroupent les femmes pour des sommes le plus souvent très modiques (à partir de $1 \mathrm{~F}$ par jour). Dans le contexte de détresse économique postcolonial, c'est le seul moyen de disposer à intervalles réguliers d'une somme d'argent aussitôt placée dans le système de dons et contre-dons qui forme l'armature de la sociabilité dakaroise (et sénégalaise). La tontine, ancrée dans des gains quotidiens minuscules, rend possible la vie sociale et élève les marchandes un peu au-dessus de la précarité (pp. 109-122). Car, trop souvent, la « dépense » assurée par l'époux fait défaut et l'épouse use ses forces à sauver la face du mari indigent. Elle s'endette pour offrir les cadeaux nécessaires aux fêtes et aux événements familiaux; elle n'a pour compensation que la satisfaction d'être " fatiguée ", d'avoir assuré jusqu'au bout son devoir de mère et d'épouse.

5 Malgré une approche qui refuse l'essentialisme pour mieux voir comment les rapports sociaux entre hommes et femmes "sont renégociés en permanence » (p. 162), Mireille Lecarme-Frassy se heurte plus qu'elle ne le voudrait à la permanence de cette sujétion au pouvoir masculin à laquelle les mères préparent leurs filles dès l'enfance. Certes, les discours de légitimation proférés en toute occasion par les femmes elles-mêmes sont régulièrement contredits par la réalité de leur pouvoir concret, matériel et économique. À la maison et dans la cour cependant, leur agressivité latente est constamment niée par une docilité apparente, résultat d'une contrainte de tous les instants. Les différends, s'il y en a, doivent être réglés hors de portée des oreilles indiscrètes, sinon le mari perd la face. Et même si le pouvoir des hommes est entretenu par le mutisme des femmes (p.178), il demeure l'idéal intangible, source de commentaires, de craintes et de menaces volontiers livrés à l'ethnologue par ses informateurs masculins. Dans une société en pleine mutation, ce sont les codes 
maritaux venus des villages qui manifestent le plus fortement leur permanence ; la dot, payée par les hommes, pèse sur les femmes comme une dette sans fin.

Dix ans plus tard, l'argent apporté par des bailleurs de fonds étrangers accompagne la normalisation de ce quartier précaire et induit de nouvelles et lourdes charges monétaires par l'achat nécessaire de parcelles d'habitation. Il faut contribuer à des coopératives bien plus contraignantes que les tontines. Toutes les astuces quotidiennes mises en place par l'ingéniosité et la polyvalence de l'économie informelle sont mises à mal. La monétarisation, aggravée par la dévaluation de 1994, intervient alors que le marché est abandonné et que les vendeuses, ayant perdu leur lieu de sociabilité, sont dispersées aux carrefours. Les amies que retrouve Mireille Lecarme-Frassy racontent leur présent, devenu plus précaire et parlent de leur avenir, plus incertain ; elles sont hantées par la crainte de ne plus pouvoir assurer leurs obligations sociales. Les remboursements des prêts consentis par l'aide internationale entraînent des amendes à chaque retard. Ainsi se fait l'éducation à l'économie mondiale : par l'appauvrissement et dans la douleur. Il faut lire ce livre et le faire lire aux bailleurs de fonds.

\section{AUTEUR}

MARIE-CLAUDE DUPRÉ

CNRS, CRENAM, Géographie française, Saint-Étienne. 